\title{
Inflammatory Marker sTREM-1 Reflects the Clinical Stage and Respiratory Tract Obstruction in Allergic Asthma Bronchiale Patients and Correlates with Number of Neutrophils
}

\author{
Maria Bucova, ${ }^{1}$ Magda Suchankova, ${ }^{1}$ Martin Dzurilla, ${ }^{1}$ Mojmir Vrlik, ${ }^{2}$ Helena Novosadova, ${ }^{3}$ \\ Eva Tedlova, ${ }^{3}$ Stefan Urban, ${ }^{3}$ Edita Hornakova, ${ }^{3}$ Marianna Seligova, ${ }^{3}$ \\ Vladimira Durmanova, ${ }^{1}$ Peter Penz, ${ }^{4}$ Juraj Javor, ${ }^{1}$ and Ema Paulovicova ${ }^{5}$ \\ ${ }^{1}$ Institute of Immunology, Faculty of Medicine, Comenius University, 81372 Bratislava, Slovakia \\ ${ }^{2}$ Centre of Immunology, 03659 Martin, Slovakia \\ ${ }^{3}$ Institute of Pneumology and Phthisiology, Faculty of Medicine, Comenius University, University Hospital, 81372 Bratislava, Slovakia \\ ${ }^{4}$ Institute of Internal Medicine I, Faculty of Medicine, Comenius University, University Hospital, 81372 Bratislava, Slovakia \\ ${ }^{5}$ Institute of Chemistry, Slovak Academie of Science, Centre of Excellence Glycomed, 84541 Bratislava, Slovakia \\ Correspondence should be addressed to Maria Bucova, maria.bucova@gmail.com
}

Received 16 January 2012; Revised 20 April 2012; Accepted 21 April 2012

Academic Editor: Giamila Fantuzzi

Copyright (c) 2012 Maria Bucova et al. This is an open access article distributed under the Creative Commons Attribution License, which permits unrestricted use, distribution, and reproduction in any medium, provided the original work is properly cited.

\begin{abstract}
The knowledge that asthma is an inflammatory disorder has prompted us to investigate the plasma levels of a new inflammatory marker sTREM-1 that is released from the surfaces of activated neutrophils and monocytes. The plasma levels of sTREM-1 were analysed by a sandwich ELISA test in the cohort of 76 patients with allergic asthma bronchiale and 39 healthy controls. Our results revealed more than 3.5 times higher levels of sTREM-1 in AB patients $(92.3 \mathrm{pg} / \mathrm{mL} \pm 125.6)$ compared with healthy subjects $(25.7 \mathrm{pg} / \mathrm{mL} \pm 9.2 ; P=0.0001)$. Higher levels of sTREM-1 were found also in patients with exacerbated $A B$ $(170.5 \mathrm{pg} / \mathrm{mL} \pm 78.2)$ compared with nonexacerbated $\mathrm{AB}$ patients $(59.1 \pm 78.2 ; P<0.0001)$, patients with respiratory tract obstruction $(176.4 \mathrm{pg} / \mathrm{mL} \pm 177.8)$, than those without obstruction $(51.99 \mathrm{pg} / \mathrm{mL} \pm 64.0 ; P<0.0001)$ and patients with anti-IgE therapy $(P<0.0001)$. Levels of sTREM-1 correlated with number of leucocytes $(P=0.002)$, and absolute number of neutrophils $(P=0.001)$. Elevated plasma levels of sTREM-1 reflect the severity, state of exacerbation, presence of respiratory tract obstruction in $\mathrm{AB}$ patients and together with increased number of neutrophils point to the role of neutrophils in inflammation accompanying $\mathrm{AB}$.
\end{abstract}

\section{Introduction}

TREM-1 (Triggering receptor expressed on myeloid cells), first described in 2000 [1], belongs to a family related to the natural killer cell receptors and is constitutively expressed on the surface of myeloid cells neutrophils, monocytes, and macrophages [2]. Although the biochemical structure of TREM-1 ligands remains to be identified, some studies suggest for inflammatory response products participation. Expression of TREM-1 is upregulated after stimulation with bacterial and fungal products, and also sterile noninfectious stimuli-inflammatory cytokines or other mediators of inflammation, for example, prostaglandin E2 (PGE2) and some endogenous substances released during inflammation-damage-associated molecular patterns $[2-$ 6]. HMGB1 (high mobility group box 1 protein) and HSP70 (Heat shock protein) released from necrotic cells function as endogenous danger signals, and TREM-1 is involved in mediating proinflammatory responses [7]. Other results [6] provide evidence that TREM-1 may contribute the development of nonmicrobial inflammatory diseases through the enhancement of inflammatory responses [6]. Hypoxia itself modulates the gene expression profile in human mature dendritic cells, and TREM-1 molecule was defined as a novel hypoxic marker in vitro and in vivo [8]. The involvement of TREM-1 activation in the enhancement of inflammatory response mediated by Toll-like receptor- 2 and -4 stimulation was detected [9]. 
Myeloid cells activation upon a ligand binding to this receptor generally results in inflammatory response amplification, enhanced production of proinflammatory mediators, mainly of tumour necrosis factor-alfa (TNF- $\alpha$ and of interleukin-8 (IL-8) [2, 10], increased expression of costimulatory molecules on the surface of macrophages, and enhanced antigen presentation that triggers T-cell proliferation $[1,10]$. Neutrophils activated through TREM-1 enhance their respiratory burst activity, degranulation, phagocytosis, release of myeloperoxidase, and IL-8, respectively [11]. TREM-1 by propagating inflammatory responses in inflammatory diseases thus accelerates not only the immune system activation, but also tissue destruction [6]. However, antiinflammatory cytokines synergistically inhibit its expression $[10,12]$.

The membrane form of TREM-1 can be cleaved from the surface of activated myelocytes by plasma metalloproteinases and its ectodomain is released into microenvironment [13]. This soluble TREM-1 molecule (sTREM-1) could act as a downregulator of inflammation-binding to the natural ligand, sTREM-1 prevents its binding to the membrane TREM-1 and subsequent cell activation [12]. sTREM-1 can be measured in biological fluids and may be useful as a diagnostic tool. The highest levels of sTREM-1 molecules have been found in patients with sepsis [14] and other inflammatory diseases caused mainly by extracellular microorganisms-bacteria and fungi [15-18], as well as inflammatory states of noninfectious origin, for example, rheumatoid arthritis $[19,20]$.

Knowledge that asthma is an inflammatory disorder [21] has prompted us to investigate the plasma levels of sTREM-1 in patients suffering from allergic asthma bronchiale.

\section{Subjects and Methods}

76 patients suffering from asthma bronchiale $(\mathrm{AB})$ (32 men, 44 woman), mean age $=37.4 \pm 21.4$ ) were enrolled in our study. 28 out of them suffered from a mild intermittent $\mathrm{AB}, 18$ from a mild persistent $\mathrm{AB}, 14$ from a moderate persistent $A B$, and 16 from a severe persistent $A B$. Inclusion criteria for asthma stage classification were according the Global Initiative for Asthma (GINA) guidelines [22]. Out of all $\mathrm{AB}$ patients, 25 patients were in acute exacerbation $(\mathrm{EAB})$, the rest of them (51) were without acute exacerbation (non-exacerbated AB-NEAB). $30 \mathrm{AB}$ patients suffered from respiratory tract obstruction, 46 were without respiratory tract obstruction. All patients were treated with corticosteroids, 11 patients with severe persistent $\mathrm{AB}$ were on antiIgE monoclonal antibody (Omalizumab) therapy.

Patients originated from specialized allergo-immunological outpatients' departments. Exacerbated AB patients with moderate persistent and severe persistent $\mathrm{AB}$ were in the care of Institute of Pneumology and Phthisiology, Comenius University, University Hospital in Bratislava.

All patients were carefully examined by their physicians, they underwent spirometric examinations, bronchoprovocation test, allergen skin tests, and levels of total IgE were detected too. Height and body mass of patients were measured and the body mass index was calculated for each patients.

Spirometry was measured by pneumotachograph Masterscope Masterscreen (Jaeger). The examination consisted of minimally three valid forced expiratory maneuvers after a maximum inspiration. Expirium lasted at least 8-10 seconds. The largest forced vital capacity (VC) was taken into account. Reference values were according to publication Kristufek et al. [23]. The presence of airway obstruction was defined according to criteria of the European Respiratory Society [24], when the ratio of forced expiratory volume in one second $\left(\mathrm{FEV}_{1}\right)$ to vital capacity (VC), $\left(\mathrm{FEV}_{1} / \mathrm{VC}\right)$, was less than $88 \%$ of the reference value in men and less than $89 \%$ of the reference value in women. Degrees of obstructive ventilatory disorders were defined according to the decrease of $\mathrm{FEV}_{1}$ (forced expiratory volume in one second) as follows: mild degree (mild obstructive ventilatory disorder): 60\% of the reference value-lower limit of normal, moderate degree (moderate obstructive ventilatory disorder): 59\%-45\% of the reference value, and severe degree (severe obstructive ventilatory disorder): less than $45 \%$ of the reference value.

We could not always obtain complete results of spirometry from each patient. However, medical reports with diagnostic conclusions of these tests, that is, asthma bronchiale with mild, moderate, or severe degree of obstructive ventilatory disorder, respectively, were available for each patients. These data enabled us to divide patients into two groups. One group represented patients without obstructive ventilatory disorder, the second included patients with mild, moderate, and severe obstructive ventilatory disorder. So, in statistic evaluation, the presence of bronchoconstriction was defined as nominal variable (0-without bronchoconstriction, 1-with bronchoconstriction).

Bronchoprovocation tests were performed with metacholine according to American Thoracic Society [25]. The bronchial hyperreactivity (hyperresponsiveness) was considered when $\mathrm{FEV}_{1}$ fell by $20 \%$ after metacholine dose of $8 \mathrm{mg} / \mathrm{mL}\left(\mathrm{PC}_{20}<8 \mathrm{mg} / \mathrm{mL}\right)$.

The study was approved by the Local Ethical Committee of Faculty of Medicine Comenius University in Bratislava and written informed consent was obtained from all patients.

The total plasma IgE level was determined in all patients by an electrochemiluminescence method (Modular Analytics E170, Roche, USA). Patients were assessed for both total and differential blood cell counts (total numbers of leucocytes, red blood cells, platelets, absolute, and relative number of neutrophils, lymphocytes, monocytes, eosinophils, and basophils by an optic flow cytometry (Sysmex XT 1800i (Sysmex Corporation). Plasma levels of CRP (C-reactive protein) were detected turbidimetrically (Advia 2 400, Siemens) directly at the day of blood collection. All aforementioned laboratory examinations were done in central laboratory (Medirex, Ltd., Bratislava).

The control group of healthy subjects represented 39 volunteers ( 21 men, 18 woman; mean age \pm STD $=37.3 \pm$ 13.7). None of these subjects suffered from $A B$ and all of them were without any history of pollen allergy.

Plasma levels of sTREM-1 were investigated by a sandwich Elisa test (Human sTREM-1 ELISA; R\&D, Quantikine, 
Minneapolis, USA), exactly according to instructions of the manufacturer.

\section{Statistical Analysis}

The one-sample Kolmogorov-Smirnov test was used to determine whether the investigated population followed a normal distribution. Either Anova or nonparametric MannWhitney $U$-test were used to determine the difference and the statistical significance. The association of sTREM1 plasma levels with clinical stage of $\mathrm{AB}$ was evaluated by Kruskal Wallis test. For correlation analysis of nonparametric continuals and nominal variables the Spearmans' two-tailed test was used. ROC Curve analysis was used to determine the specificity and sensitivity of sTREM-1 test. For multiple comparison, the Bonferonni correction was used and only a $P$ value $<0.005$ was considered statistically significant.

\section{Results}

The obtained results can be summarised as follows.

4.1. Age of Healthy Subjects and Patients in Different Subgroups of $A B$. The group of $A B$ patients was divided into the mild intermittent $A B$, the mild persistent $A B$, the moderate persistent $A B$, and the severe persistent $A B$ subgroups. When we analysed age of patients in the particular subgroups, we found a significant correlation between the age and severity of the disease (Table 1). The results are listed as mean and standard deviation.

The rest of results are listed as median and interquartile range (IQR).

4.2. Comparison of Plasma sTREM-1 between AB Patients and Healthy Controls. Statistically highly significantly elevated plasma levels of sTREM-1 in AB patients were observed $(92.3 \mathrm{pg} / \mathrm{mL} \pm 125.6)$ compared to those in healthy subjects without $\mathrm{AB}$ and any pollen allergy $(25.7 \mathrm{pg} / \mathrm{mL} \pm 9.2 ; P=$ 0.0001 , Table 2, Figure 1). Kruskal-Wallis test revealed a significant association between the plasma levels of sTREM1 and clinical stages of $\mathrm{AB}(P<0.005)$. Plasma levels of sTREM-1 were statistically significantly higher in moderate and severe $\mathrm{AB}$ patients comparing to mild intermittent $\mathrm{AB}$ patients.

4.3. Comparison of Plasma sTREM-1 between AB Patients with and without Acute Exacerbation. Statistically significantly higher plasma levels of sTREM-1 were found in exacerbating $\mathrm{AB}$ patients $(\mathrm{EAB})$ compared to those without $\mathrm{AB}$ exacerbation $(\mathrm{NEAB}): \mathrm{EAB}=170.5 \pm 78.2 \mathrm{pg} / \mathrm{mL}$; NEAB $=59.1 \mathrm{pg} / \mathrm{mL} \pm 78.2 \mathrm{pg} / \mathrm{mL} ; P=0.0001$, Table 2). The EAB patients experienced also higher numbers of leukocytes $(P=0.014)$ and absolute number of neutrophils $(P=$ 0.014 , Table 3). However, the relative number of eosinophils were statistically significantly higher in nonexacerbating $\mathrm{AB}$ patients $(P=0.045)$. Both, the absolute and relative number of monocytes and lymphocytes were lower in the $\mathrm{EAB}$

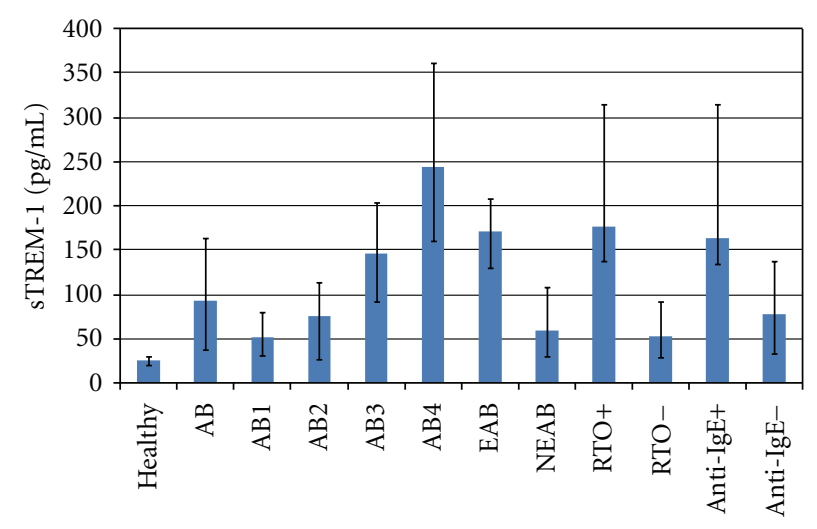

FIGURE 1: Plasma levels of sTREM-1 in healthy subjects and asthma bronchiale patients $A B$ : asthma bronchiale, $A B 1$ : mild intermittent $A B, A B 2$ : mild persistent $A B, A B 3$ : moderate persistent $A B, A B 4$ : severe persistent $A B, E A B$ : exacerbated $A B, N E A B$ : nonexacerbated $\mathrm{AB}, \mathrm{RTO}^{+}$: asthma with respiratory tract obstruction, $\mathrm{RTO}^{-}$: asthma without respiratory tract obstruction, Anti-IgE+: asthma with anti-IgE therapy, Anti-IgE-: asthma without anti-IgE therapy.

patients, however, these differences did not reach statistical significance.

4.4. Comparison of Plasma sTREM-1 between AB Patients with and without Respiratory Tract Obstruction. Comparing plasma levels of sTREM-1 in the group of $\mathrm{AB}$ patients suffering from respiratory tract obstruction $\left(\mathrm{RTO}^{+}\right)$with those in the RTO negative group $\left(\mathrm{RTO}^{-}\right)$, statistically significant differences were observed $\left(\mathrm{RTO}^{+}=176.4 \mathrm{pg} / \mathrm{mL} \pm 177.8\right.$; $\mathrm{RTO}^{-}=52.0 \mathrm{pg} / \mathrm{mL} \pm 64.0 ; P<0,0001$, Table 2). Patients with respiratory tract obstruction had also higher plasma levels of CRP $(P=0.027)$ and plasma levels of sTREM-1 calculated per one myelocyte (i.e., neutrophil and monocyte, $P=0.011)$ than those without respiratory tract obstruction (Table 4).

4.5. Correlation Test. Spearman's correlation test (Table 5) showed that plasma levels of sTREM-1 significantly correlated with the clinical stage of $\mathrm{AB}(P=0.0001)$, the degree of respiratory tract obstruction $(P=0.0001)$, and the presence of anti-IgE omalizumab therapy $(P=0.0001)$. The plasma levels of sTREM-1 in AB patients also significantly correlated with the number of leukocytes $(P=0.002)$ and the absolute number of neutrophils $(P=0.001)$. The correlation of sTREM-1 with increased number of neutrophils belong to rather notable findings. Eventually, the levels of sTREM-1 significantly correlated with those calculated for one myelocyte $(P=0.0001)$.

4.6. Sensitivity and Specificity of sTREM-1 Test. The sensitivity and specificity for sTREM-1 concentrations can be found in Figure 2, and Table 6. The asymptomatic lower bound confidence interval for this test was 0.78 and upper bound confidence interval 0.93. 
TABLE 1: Characteristics of investigated asthma bronchiale patients.

\begin{tabular}{|c|c|c|c|c|}
\hline Patients & Number & $(\%)$ & Age $($ mean \pm STD $)$ & $P($ ANOVA $)$ \\
\hline Healthy subjects & 19 & 100 & $37.3 \pm 13.7$ & \\
\hline $\mathrm{AB}$ & 76 & 100 & $37.4 \pm 21.4$ & $>0.05$ \\
\hline Mild intermittent $\mathrm{AB}(\mathrm{AB} 1)$ & 28 & 36.8 & $22.0 \pm 10.6$ & \\
\hline Mild persistent $\mathrm{AB}$ (AB2) & 18 & 23.7 & $29.7 \pm 15.7$ & $>0.05^{*}$ \\
\hline Moderate persistent $\mathrm{AB}(\mathrm{AB} 3)$ & 14 & 18.4 & $48.1 \pm 26.2$ & $<0.001^{*}$ \\
\hline Severe persistent $A B(A B 4)$ & 16 & 21.1 & $55.5 \pm 9.7$ & $<0.001^{*}$ \\
\hline Exacerbated $\mathrm{AB}$ & 25 & 32.9 & $54.7 \pm 19.0$ & \\
\hline Nonexacerbated $\mathrm{AB}$ & 51 & 67.1 & $30.0 \pm 18.2$ & $<0.0001^{* *}$ \\
\hline Respiratory tract obstruction $\left(\mathrm{RTO}^{+}\right)$ & 30 & 39.5 & $52.1 \pm 19.2$ & \\
\hline Without RTO $\left(\mathrm{RTO}^{-}\right)$ & 46 & 60.5 & $24.7 \pm 12.9$ & $<0.001^{* *}$ \\
\hline Anti-IgE therapy & 11 & 14.5 & $54.1 \pm 13.0$ & \\
\hline Without anti-IgE therapy & 65 & 85.5 & $34.6 \pm 21.2$ & $<0.001^{* *}$ \\
\hline
\end{tabular}

$\mathrm{AB}$ : asthma bronchiale, ${ }^{*}$ significance between $\mathrm{AB} 2$ versus $\mathrm{AB} 1, \mathrm{AB} 3$ versus $\mathrm{AB} 1, \mathrm{AB} 4$ versus $\mathrm{AB} 1,{ }^{*} *$ significance between age of patients in exacerbated versus nonexacerbated asthma, asthma with versus without respiratory tract obstruction, patients with versus without anti-IgE therapy.

TABLE 2: Plasma levels of sTREM-1 in healthy subjects and asthma bronchiale patients.

\begin{tabular}{|c|c|c|c|c|}
\hline Patients & $\begin{array}{c}\text { Age (years) } \\
(\text { mean } \pm \text { STD })\end{array}$ & $\begin{array}{l}\text { sTREM-1 } \\
(\mathrm{pg} / \mathrm{mL}) \\
\text { (Median) }\end{array}$ & sTREM-1 (IQR) & Mann-Whitney (2-tailed) $P$ \\
\hline Healthy subjects & $37.3 \pm 13.7$ & 25.7 & 9.2 & \\
\hline $\mathrm{AB}$ patients & $37.4 \pm 21.4$ & 92.3 & 125.6 & $<0.0001$ \\
\hline $\begin{array}{l}\text { Mild } \\
\text { intermittent } A B \\
(\mathrm{AB} 1)\end{array}$ & $22.0 \pm 10.6$ & 50.8 & 49.2 & \\
\hline $\begin{array}{l}\text { Mild persistent } \\
\mathrm{AB}(\mathrm{AB} 2)\end{array}$ & $29.7 \pm 15.7$ & 75.7 & 87.7 & $=0.333^{*}$ \\
\hline $\begin{array}{l}\text { Moderate } \\
\text { persistent } \mathrm{AB} \\
(\mathrm{AB} 3)\end{array}$ & $48.1 \pm 26.2$ & 145.6 & 111.4 & $=0.001^{*}$ \\
\hline $\begin{array}{l}\text { Severe persistent } \\
\mathrm{AB}(\mathrm{AB} 4)\end{array}$ & $55.5 \pm 9.7$ & 244.0 & 201.8 & $<0.005^{*}$ \\
\hline $\begin{array}{l}\text { Kruskal-Wallis } \\
\text { 2-tailed sg. }\end{array}$ & $P<0.005$ & & & \\
\hline $\mathrm{EAB}$ & $54.7 \pm 19.0$ & 170.5 & 78.2 & \\
\hline NEAB & $30.0 \pm 18.2$ & 59.1 & 78.2 & $<0.0001^{* *}$ \\
\hline $\begin{array}{l}\text { Respiratory } \\
\text { tract } \\
\text { obstruction } \\
\left(\mathrm{RTO}^{+}\right)\end{array}$ & $52.1 \pm 19.2$ & 176.4 & 177.8 & \\
\hline $\begin{array}{l}\text { Without RTO } \\
\left(\mathrm{RTO}^{-}\right)\end{array}$ & $24.7 \pm 13.0$ & 52.0 & 64.0 & $<0.0001^{* *}$ \\
\hline $\begin{array}{l}\text { Anti-IgE } \\
\text { therapy }\end{array}$ & $54.1 \pm 13.0$ & 163.4 & 180.1 & \\
\hline $\begin{array}{l}\text { Without } \\
\text { anti-IgE therapy }\end{array}$ & $34.6 \pm 21.2$ & 76.9 & 104.3 & $<0.0001^{* *}$ \\
\hline
\end{tabular}

AB: asthma bronchiale, STD: standard deviation, IQR: interquartile range, *significance between $\mathrm{AB} 2$ versus $\mathrm{AB} 1, \mathrm{AB} 3$ versus $\mathrm{AB} 1, \mathrm{AB} 4$ versus $\mathrm{AB} 1$, EAB: exacerbated asthma bronchiale, NEAB: non-exacerbated asthma bronchiale, $\mathrm{RTO}^{+}$: asthma with respiratory tract obstruction, $\mathrm{RTO}^{-}$: asthma without respiratory tract obstruction, ${ }^{* *}$ significance between exacerbated versus non-exacerbated asthma, asthma with versus without respiratory tract obstruction, patients with versus without anti-IgE therapy. 
TABLE 3: Comparison of plasma levels of investigated parameters in asthma bronchiale patients with and without exacerbation.

\begin{tabular}{lcccc}
\hline & sTREM-1 pg/mL & Leu $1 \cdot 10^{6} / \mathrm{mL}$ & Neu (abs) $1 \cdot 10^{6} / \mathrm{mL}$ & Eo $(\mathrm{rel}) \%$ \\
\hline EAB & $170.5 \pm 78.2$ & $10.1 \pm 5.9$ & $6.7 \pm 4.4$ & $1.3 \pm 4.8$ \\
NEAB & $59.1 \pm 78.2$ & $7.4 \pm 1.8$ & $4.2 \pm 2.4$ & $5.4 \pm 6.6$ \\
Mann-Whitney 2-tailed sg. & $P<0.0001$ & $P=0.014$ & $P=0.014$ & $P=0.045$ \\
\hline
\end{tabular}

Leu: leukocytes, Neu: neutrophils, Eo: eosinophils, EAB: exacerbated asthma bronchiale, NEAB: non-exacerbated asthma bronchiale.

TABLE 4: Comparison of plasma levels of investigated parameters in asthma bronchiale patients with and without respiratory tract obstruction.

\begin{tabular}{lccccc}
\hline & sTREM-1 $(\mathrm{pg} / \mathrm{mL})$ & CRP $\mathrm{mg} / \mathrm{mL}$ & Leu $1 \cdot 10^{6} / \mathrm{mL}$ & Neu (abs) $1 \cdot 10^{6} / \mathrm{mL}$ & TREM-1/myelocyte \\
\hline RTO $^{+}$ & $176.4 \pm 177.8$ & $5.8 \pm 7.4$ & $9.0 \pm 3.6$ & $5.8 \pm 3.6$ & $2.9 \pm 2.5$ \\
RTO $^{-}$ & $52.0 \pm 64.0$ & $2.5 \pm 0.9$ & $6.7 \pm 1.4$ & $3.9 \pm 1.4$ & $1.8 \pm 0.9$ \\
Mann-Whitney 2-tailed sg. & $P<0.0001$ & $P=0.027$ & $P=0.013$ & $P=0.008$ & $P=0.011$ \\
\hline
\end{tabular}

Leu: leukocytes, CRP: C-reactive protein, Neu: neutrophils, Eo: eosinophils, $\mathrm{RTO}^{+}$: asthma bronchiale with respiratory tract obstruction, $\mathrm{RTO}^{-}$: asthma bronchiale without respiratory tract obstruction.

TABLE 5: Correlations of plasma levels of sTREM-1 with investigated parameters.

\begin{tabular}{lcc}
\hline & Spearman's correlation test with sTREM-1 $(P)$ & Correlation coefficient \\
\hline Clinical stage of AB & $P=0.0001$ & 0.682 \\
Respiratory tract obstruction & $P=0.0001$ & 0.653 \\
Anti-IgE therapy & $P=0.001$ & 0.421 \\
CRP & $P=0.009$ & 0.499 \\
Total level of IgE & $P=0.032$ & 0.290 \\
Leukocytes & $P=0.002$ & 0.530 \\
Neutrophils (absolute number) & $P=0.001$ & 0.579 \\
Neutrophils (relative number) & $P=0.044$ & 0.371 \\
Lymphocytes (absolute number) & $P=0.013$ & -0.442 \\
sTREM-1 per one myelocyte & $P=0.0001$ & 0.920 \\
\hline
\end{tabular}

AB: asthma bronchiale, CRP: C-reactive protein. Taking into account more correlated parameters, statistically significant are values when $P<0.005$.

\section{Discussion}

Asthma's main features include chronic airways inflammation with a variable degree of air-flow obstruction and bronchial hyperresponsiveness, leading to paroxysmal symptoms of wheeze, cough, shortness of breath, and chest tightness [26]. Antigen-specific Th2 cells and their cytokines IL-4, IL-5, and IL-13 orchestrate the allergic inflammation in asthmatic patients [27-29]. Th17 cells and IL-23 are also involved in antigen-induced airway inflammation, granulopoiesis activation, and neutrophil recruitment mainly in severe asthma, of which neutrophil infiltration is one of the hallmarks [30-33].

In our study, we investigated the plasma levels of a new inflammatory marker sTREM-1 in pollen allergy $A B$ patients. Our results revealed more than 3.5 times higher levels of sTREM-1 in patients with $\mathrm{AB}$ compared with healthy subjects without $\mathrm{AB}$ and without history of pollen allergy $(P=0.0001)$, indicating for the presence of inflammatory process in asthma patients. The elevated levels of plasma sTREM-1 significantly correlated with clinical stage and severity of $\mathrm{AB}$ (Table 2, Figure 1). The highest levels of
sTREM-1 were found in patients with moderate and severe persistent $A B$. The association of the clinical stage of $A B$ patients with their age is documented in Table 1.

We found also significantly higher levels of sTREM-1 in $\mathrm{AB}$ patients in exacerbation (EAB) compared with nonexacerbating $\mathrm{AB}$ patients $(P<0.0001)$. The group of $\mathrm{EAB}$ patients had also significantly higher number of leukocytes $(P=0.014)$ and neutrophils $(P=0.014)$ than NEAB group of patients (Table 3 ). Respiratory tract obstruction was also followed by elevated levels of sTREM-1 $(P<0.0001$, Table 2$)$, CRP $(P=0.027)$, leukocytes $(P=0.013)$, and absolute number of neutrophils $(P=0.008$, Table 4$)$.

Investigations of plasma levels of sTREM-1 in all subjects of atopic $A B$ patients disclosed the statistically significant correlation of its levels with the clinical stage of $\mathrm{AB}$, respiratory tract obstruction, levels of CRP, the presence of anti-IgE therapy, number of leukocytes, absolute number of neutrophils, and the level of sTREM-1 calculated per one myelocyte, respectively (Table 5).

There are two papers in PubMed concerning the role of membrane TREM-1 in $A B[16,34]$, however, the levels of sTREM-1 in $A B$ patients have not been studied yet, 


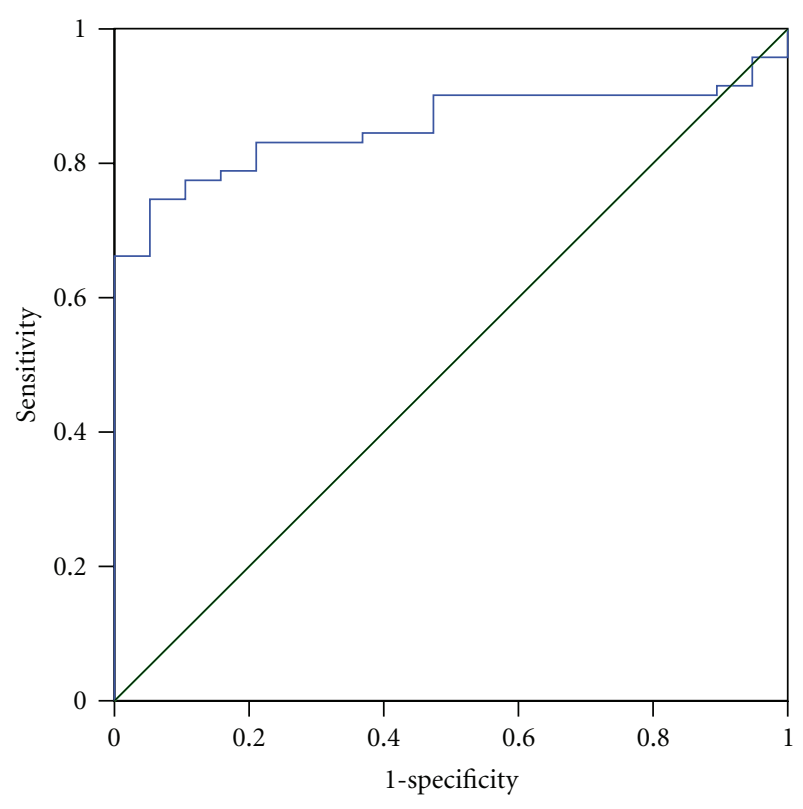

FIGURE 2: Receiver operating characteristic curve (ROC Curve) of sTREM-1 for asthma bronchiale.

so we can not compare our results. Elevated levels of sTREM-1 accompanied by increased number of neutrophils in exacerbated asthma bronchiale (Table 3), asthma with respiratory tract obstruction (Table 4), and severe forms of asthma (Table 5) in our group of atopic $\mathrm{AB}$ patients support the results and the opinion of the authors that point to an important role of neutrophils in asthma [27, 32, 33]. Although eosinophilic airway inflammation is recognized as an important feature of some patients with chronic stable asthma, neutrophils are the first cells recruited to the site of the allergic reaction and are eliminated by apoptosis during the resolution of the allergic response. Our findings of increased number of eosinophils in $\mathrm{AB}$ patients without acute exacerbation supports this fact (Table 3 ). The presence of neutrophils may influence clinical presentation and has been linked to the development of severe chronic asthma and sudden severe attacks [32]. Our results support this knowledge, increased number of neutrophils that we found in severe forms of asthma underlies this opinion. Moreover, as sTREM-1 is cleaved and released from the surfaces of activated neutrophils and monocytes, elevated plasma levels of sTREM-1 also underline the role of neutrophils in inflammation that accompaines these clinical conditions.

5.1. Conclusion. Our results show that the plasma levels of sTREM-1 are highly elevated in severe forms of asthma, reflect the clinical stage of $A B$, state of exacerbation, respiratory tract obstruction, and correlate with the number of leukocytes, mainly neutrophils. These results point to the role of neutrophils in inflammation that accompanies these clinical conditions. Our results highlight the potential usefulness of the assessment of the soluble form of TREM-1 in plasma of $\mathrm{AB}$ patients.
TABLE 6: Sensitivity and specificity of sTREM-1 test. Coordinates of the curve.

\begin{tabular}{|c|c|c|}
\hline sTREM-1 (pg/mL) & Sensitivity & Specificity \\
\hline 2.92 & 100 & 0.0 \\
\hline 10.4 & 95.8 & 0.053 \\
\hline 20.6 & 90.1 & 15.8 \\
\hline 24.9 & 90.1 & 47.4 \\
\hline 25.8 & 90.1 & 52.6 \\
\hline 27.9 & 84.5 & 63.2 \\
\hline 29.6 & 83.1 & 73.7 \\
\hline 30.3 & 83.1 & 78.9 \\
\hline 34.6 & 78.9 & 84.2 \\
\hline 36.3 & 77.5 & 84.2 \\
\hline 37.5 & 77.5 & 94.7 \\
\hline 42.8 & 74.6 & 94.7 \\
\hline 48.4 & 71.8 & 94.7 \\
\hline 49.8 & 66.2 & 100.0 \\
\hline 51.0 & 66.2 & 100.0 \\
\hline 62.7 & 60.6 & 100.0 \\
\hline 72.1 & 57.7 & 100.0 \\
\hline 87.5 & 50.7 & 100.0 \\
\hline 102.9 & 45.1 & 100.0 \\
\hline 196.6 & 16.9 & 100.0 \\
\hline 279.5 & 9.9 & 100.0 \\
\hline 494.0 & 2.8 & 100.0 \\
\hline 546.1 & 1.4 & 100.0 \\
\hline 555.4 & 0.0 & 100.0 \\
\hline
\end{tabular}

\section{Abbreviations}

AB: $\quad$ Asthma bronchiale

AB1: $\quad$ Mild intermittent asthma

AB2: $\quad$ Mild persistent asthma

AB3: $\quad$ Moderate persistent asthma

AB4: $\quad$ Severe persistent asthma

CRP: C-reactive protein

EAB: $\quad$ Exacerbated asthma bronchiale

IQR: Interquartil range

NEAB: Non-exacerbated asthma bronchiale

$\mathrm{RTO}^{+}$: With respiratory tract obstruction

$\mathrm{RTO}^{-}$: Without respiratory tract obstruction

STD: $\quad$ Standard deviation

sTREM-1: Soluble Triggering receptor expresssed on myelocytes

TREM-1: Triggering receptor expressed on myelocytes.

\section{Acknowledgment}

This work was supported by the grant VEGA 1/0574/10. 


\section{References}

[1] A. Bouchon, J. Dietrich, and M. Colonna, "Cutting edge: inflammatory responses can be triggered by TREM-1, a novel receptor expressed on neutrophils and monocytes," Journal of Immunology, vol. 164, no. 10, pp. 4991-4995, 2000.

[2] D. Barraud and S. Gibot, "Triggering receptor expressed on myeloid cell 1," Critical Care Clinics, vol. 27, no. 2, pp. 265279, 2011.

[3] C. E. Collins, D. T. La, H. T. Yang et al., "Elevated synovial expression of triggering receptor expressed on myeloid cells 1 in patients with septic arthritis or rheumatoid arthritis," Annals of the Rheumatic Diseases, vol. 68, no. 11, pp. 17681774, 2009.

[4] M. Průcha, R. Zazula, M. Müller, T. Hyánek, M. Dostál, and L. Sedláčková, "TREM-1 expression on monocytes is not a parameter specific for infectious etiology of systemic inflammatory response syndrome," Prague Medical Report, vol. 112, no. 3, pp. 205-215, 2011.

[5] E. Ferat-Osorio, N. Esquivel-Callejas, I. Wong-Baeza et al., "The increased expression of TREM-1 on monocytes is associated with infectious and noninfectious inflammatory processes," Journal of Surgical Research, vol. 150, no. 1, pp. 110-117, 2008.

[6] Y. Murakami and H. Kohsaka, "Triggering receptor expressed on myeloid cells-1 as an inflammation amplifier," Japanese Journal of Clinical Immunology, vol. 32, no. 4, pp. 242-248, 2009.

[7] R. El Mezayen, M. El Gazzar, M. C. Seeds, C. E. McCall, S. C. Dreskin, and M. R. Nicolls, "Endogenous signals released from necrotic cells augment inflammatory responses to bacterial endotoxin," Immunology Letters, vol. 111, no. 1, pp. 36-44, 2007.

[8] M. C. Bosco, D. Pierobon, F. Blengio et al., "Hypoxia modulates the gene expression profile of immunoregulatory receptors in human mature dendritic cells: identification of TREM1 as a novel hypoxic marker in vitro and in vivo," Blood, vol. 117, no. 9, pp. 2625-2639, 2011.

[9] S. Gibot, "Clinical review: role of triggering receptor expressed on myeloid cells-1 during sepsis," Critical Care, vol. 9, no. 5, pp. 485-489, 2005.

[10] J. R. Bleharski, V. Kiessler, C. Buonsanti et al., "A role for triggering receptor expressed on myeloid cells- 1 in host defense during the early-induced and adaptive phases of the immune response," Journal of Immunology, vol. 170, no. 7, pp. 3812-3818, 2003.

[11] M. P. Radsak, H. R. Salih, H. G. Rammensee, and H. Schild, "Triggering receptor expressed on myeloid cells-1 in neutrophil inflammatory responses: differential regulation of activation and survival," Journal of Immunology, vol. 172, no. 8, pp. 4956-4963, 2004.

[12] S. Gibot and F. Massin, "Soluble form of the triggering receptor expressed on myeloid cells 1: an anti-inflammatory mediator?" Intensive Care Medicine, vol. 32, no. 2, pp. 185187, 2006.

[13] V. Gómez-Piña, A. Soares-Schanoski, A. Rodríguez-Rojas et al., "Metalloproteinases shed TREM-1 ectodomain from lipopolysaccharide- stimulated human monocytes," Journal of Immunology, vol. 179, no. 6, pp. 4065-4073, 2007.

[14] S. Gibot, A. Cravoisy, M. N. Kolopp-Sarda et al., "Timecourse of sTREM (soluble triggering receptor expressed on myeloid cells)-1, procalcitonin, and C-reactive protein plasma concentrations during sepsis," Critical Care Medicine, vol. 33, no. 4, pp. 792-796, 2005.

[15] G. D. Amatngalim, A. Nijnik, P. S. Hiemstra, and R. E. W. Hancock, "Cathelicidin peptide LL-37 modulates TREM-1 expression and inflammatory responses to microbial compounds," Inflammation, vol. 34, no. 5, pp. 412-425, 2010.

[16] K. F. Buckland, H. Ramaprakash, L. A. Murray et al., "Triggering receptor expressed on myeloid cells-1 (TREM-1) modulates immune responses to aspergillus fumigatus during fungal asthma in mice," Immunological Investigations, vol. 40, no. 7-8, pp. 692-722, 2011.

[17] C. K. How, S. K. Hou, H. C. Shih et al., "Usefulness of triggering receptor expressed on myeloid cells-1 in differentiating between typical and atypical community-acquired pneumonia," American Journal of Emergency Medicine, vol. 29, no. 6, pp. 626-631, 2011.

[18] M. Wu, A. Peng, M. Sun et al., "TREM-1 amplifies corneal inflammation after Pseudomonas aeruginosa infection by modulating toll-like receptor signaling and Th1/Th2-type immune responses," Infection and Immunity, vol. 79, no. 7, pp. 2709-2716, 2011.

[19] T.-H. Kim, S. J. Choi, Y. H. Lee, G. G. Song, and J. D. Ji, "Soluble triggering receptor expressed on myeloid cells-1 as a new therapeutic molecule in rheumatoid arthritis," Medical Hypotheses, vol. 78, no. 2, pp. 270-272, 2012.

[20] J. Kuai, B. Gregory, A. Hill et al., "TREM-1 expression is increased in the synovium of rheumatoid arthritis patients and induces the expression of pro-inflammatory cytokines," Rheumatology, vol. 48, no. 11, pp. 1352-1358, 2009.

[21] T. R. Myers and L. Tomasio, "Asthma: 2015 and beyond," Respiratory Care, vol. 56, no. 9, pp. 1389-1407, 2011.

[22] E. D. Bateman, S. S. Hurd, P. J. Barnes et al., "Global strategy for asthma management and prevention: GINA executive summary," European Respiratory Journal, vol. 31, no. 1, pp. 143-178, 2008.

[23] P. Kristufek, M. Brezina, and P. Ciutti, "Reference values and modelling of lung function development as a transcendent function of age, body height and mass," Clinical Respiratory Physiology, vol. 23, no. 2, pp. 139-147, 1987.

[24] N. M. Siafakas, P. Vermeire, N. B. Pride et al., "Optimal assessment and management of chronic obstructive pulmonary disease (COPD)," European Respiratory Journal, vol. 8, no. 8, pp. 1398-1420, 1995.

[25] R. O. Crapo, R. Casaburi, A. L. Coates et al., "Guidelines for methacholine and exercise challenge testing-1999," American Journal of Respiratory and Critical Care Medicine, vol. 161, no. 1, pp. 309-329, 2000.

[26] S. Pakhale, S. Mulpuru, and M. Boyd, "Optimal management of severe/refractory asthma," Clinical Medicine Insights, vol. 5, no. 1, pp. 37-47, 2011.

[27] H. Nakajima and K. Hirose, "Role of IL-23 and Th17 cells in airway inflammation in asthma," Immune Network, vol. 10, no. 1, 2010, http://www.ksimm.or.kr.

[28] H. Wakashin, K. Hirose, Y. Maezawa et al., "IL-23 and Th17 cells enhance Th2-cell-mediated eosinophilic airway inflammation in mice," American Journal of Respiratory and Critical Care Medicine, vol. 178, no. 10, pp. 1023-1032, 2008.

[29] A. B. Mukherjee and Z. Zhang, "Allergic asthma: influence of genetic and environmental factors," Journal of Biological Chemistry, vol. 286, no. 38, pp. 32883-32889, 2011.

[30] M. Buc, M. Dzurilla, M. Vrlik, and M. Bucova, "Immunopathogenesis of bronchial asthma," Archivum Immunologiae et Therapiae Experimentalis, vol. 57, no. 5, pp. 331-344, 2009. 
[31] N. R. Bhakta and P. G. Woodruff, "Human asthma phenotypes: from the clinic, to cytokines, and back again," Immunological Reviews, vol. 242, no. 1, pp. 220-232, 2011.

[32] J. Monteseirín, "Neutrophils and asthma," Journal of Investigational Allergology and Clinical Immunology, vol. 19, no. 5, pp. 340-354, 2009.

[33] A. Jatakanon, C. Uasuf, W. Maziak, S. Lim, K. F. Chung, and P. J. Barnes, "Neutrophilic inflammation in severe persistent asthma," American Journal of Respiratory and Critical Care Medicine, vol. 160, no. 5, pp. 1532-1539, 1999.

[34] C. M. Hogaboam, K. J. Carpenter, J. M. Schuh, and K. F. Buckland, "Aspergillus and asthma-any link?" Medical Mycology, vol. 43, no. 1, pp. S197-S202, 2005. 


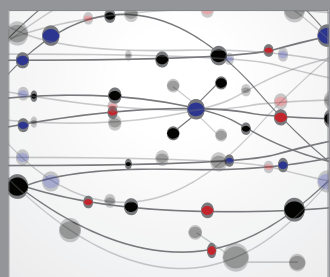

The Scientific World Journal
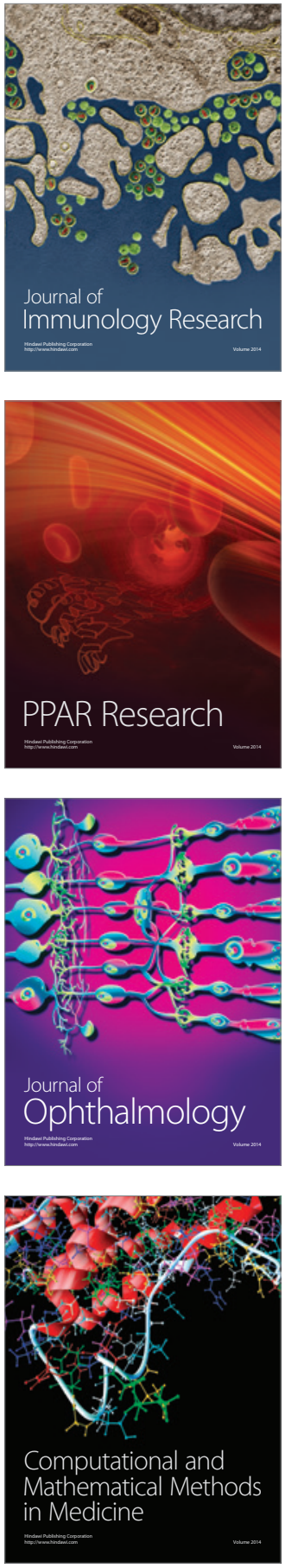

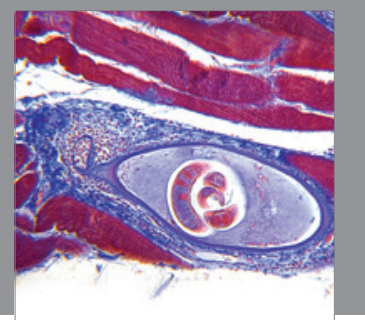

Gastroenterology

Research and Practice
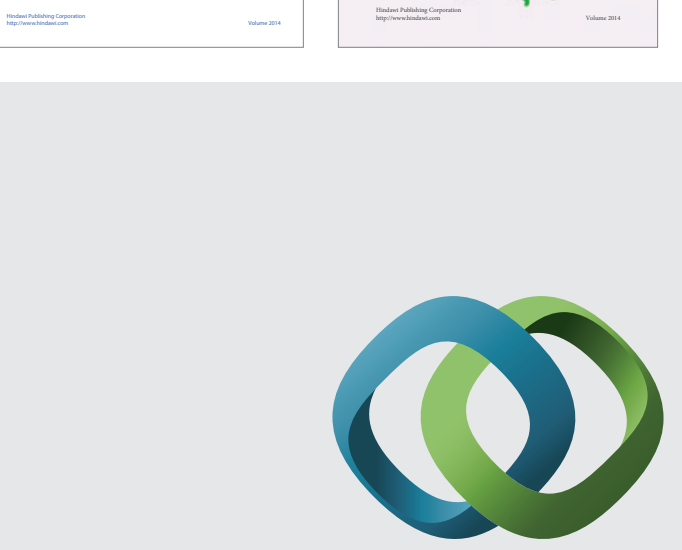

\section{Hindawi}

Submit your manuscripts at

http://www.hindawi.com
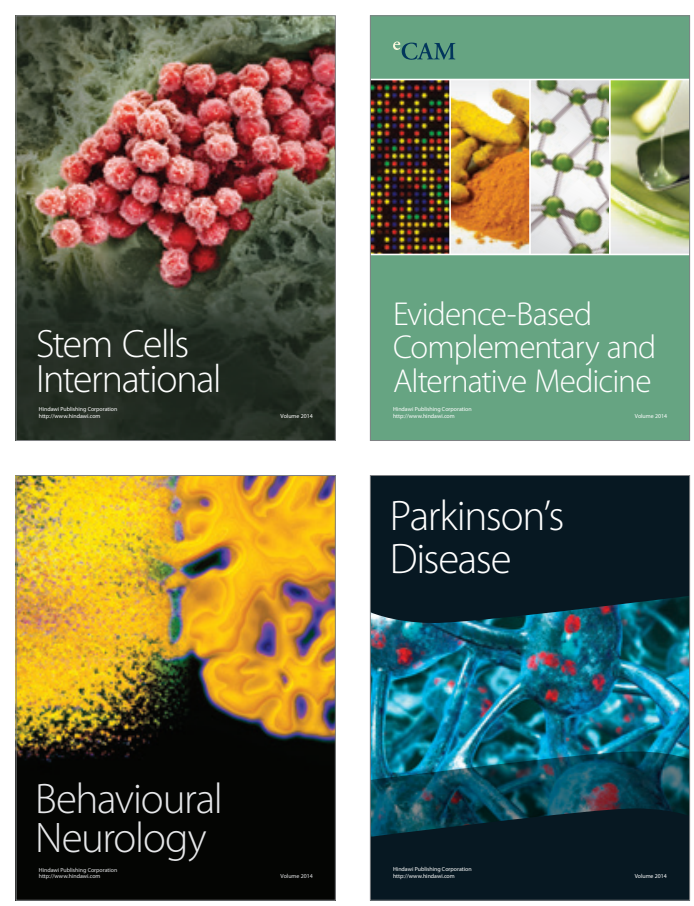

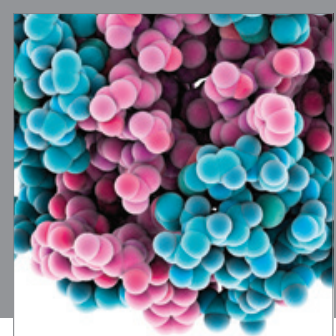

Journal of
Diabetes Research

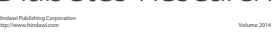

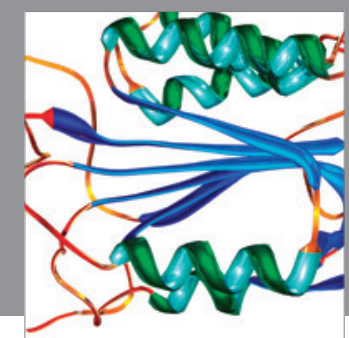

Disease Markers
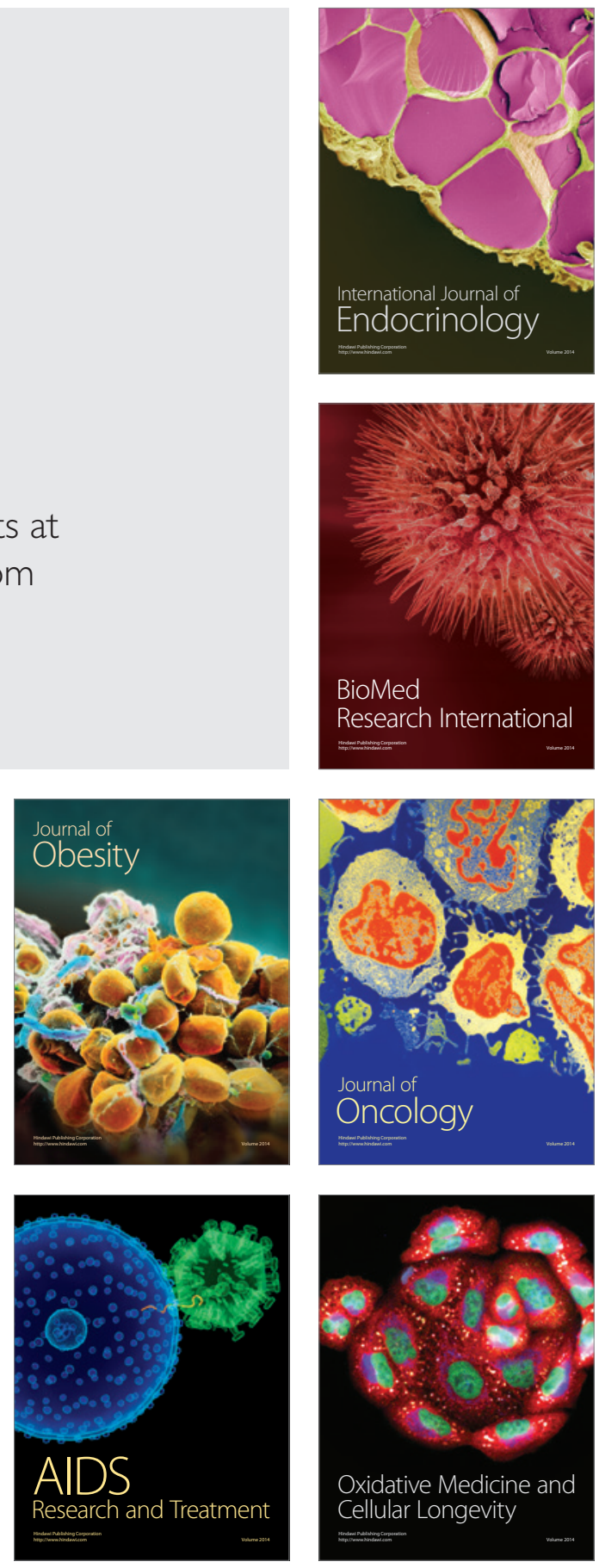